\title{
PENGARUH PENAMBAHAN LARUTAN ALKALI DALAM PROSES DEKAFEINISASI BIJI KOPI KERING TERHADAP KARAKTRISTIK FISIKOKIMIA KOPI BUBUK
}

\author{
Ruri Wijayanti dan Malse Anggia \\ Program Studi Teknologi Industri Pertanian Universitas Dharma Andalas \\ Email: ruri.wj@unidha.ac.id
}

\begin{abstract}
ABSTRAK
Kandungan kafein didalam kopi yang cukup tinggi jika dikonsumsi secara berlebihan dapat membahayakan kesehatan. Tujuan penelitian ini adalah untuk mengetahui pengaruh penambahan larutan alkali terhadap karakteristik fisiko kimia kopi bubuk yang dihasilkan dan menentukan konsentrasi alkali yang paling tepat digunakan agar diperoleh kadar kafein dan mutu kopi bubuk yang sesuai dengan SNI. Rancangan yang digunakan dalam penelitian ini adalah Rancangan Acak Lengkap dengan pola faktorial $10 \times 1$ dengan 3 kali ulangan. Faktor perlakuannya adalah larutan alkali ( $\mathrm{NaOHdan} \mathrm{Na}_{2} \mathrm{CO}_{3}$ ) dengan 5 taraf yakni $\mathrm{NaOH}$ (Konsentrasi 3, 3.5, 4, 4.5, dan 5\%) dan $\mathrm{Na}_{2} \mathrm{CO}_{3}$ (Konsentrasi 6, 6.5, 7, 7.5 dan 8\%). Parameter yang diuji diantaranya adalah kadar air, kadar abu, dan kadar kafein. Hasil penelitian menunjukkan bahwa penambahan larutan alkali memberikan pengaruh yang nyata terhadap kadar air, kadar abu dan penurunan kadar kafein bubuk kopi yang dihasilkan. Perlakuan terbaik terdapat pada perlakuan penambahan $\mathrm{Na}_{2} \mathrm{CO}_{3} 7 \%$ dengan kadar air $1,5756 \%$, kadar abu $4,7155 \%$ dan kadar kafein $0,978 \%$

Kata kunci-larutan alkali; dekafeinasi; kopi bubuk
\end{abstract}

\section{PENDAHULUAN}

Kopi merupakan salah satu komoditi ekspor dari sektor perkebunan yang sangat menjanjikan, terutama untuk menambah devisa negara dan menunjang perekonomian masyarakat. Hal ini ditunjukkan dengan jumlah ekspor Indonesia pada tahun 2015 dengan volume 502,021 ton atau senilai US\$ 1.197.735 (Badan Pusat Statistik, 2016). Sumatera Barat merupakan salah satu penyokong pasar ekspor di Indonesia. Minuman ini ternyata tidak hanya digemari oleh masyarakat dunia tetapi juga masyarakat Indonesia sendiri. Hal ini tidak terlepas dari rasa yang nikmat, dan aroma yang khas serta sejuta manfaat yang dapat dirasakan diantaranya mampu menyegarkan badan sipeminumnya.

Senyawa yang berperan sebagai bahan penyegar yang terkandung didalam kopi adalah Kafein. Kafein mudah larut didalam air, berentuk kristal, dan memberikan rasa pahit pada kopi serta dapat menurunkan rasa sakit karena memiliki manfaat sebagai obat analgetik. Hal ini diakibatkan oleh senyawa kafein ini mampu menstimulasi susunan syaraf pusat, relaksasi otot polos terutama otot polos bronkus dan stimulasi otot jantung (Hanifah dan Kurniawati, 2013).Namun dibalik sisi positif yang dimilikinya, kafein memiliki sisi negatif bagi beberapa orang. Apabila dikonsumsi berlebihan, maka dapat meningkatkan ketegangan otot, merangsang kerja jantung dan meningkatkan sekresi asam lambung. Hal ini akan membahayakan khususnya bagi orang dengan riwayat maag atau pun jantung. Maka dari itu diperlukan suatu metode untuk menurunkan kadar kafein didalam biji kopi dengan harapan didapatkannya kopi bubuk dengan kadar kafein rendah.

Proses pengurangan kandungan kafein di dalam bahan pertanian ini lebih dikenal dengan istilah Dekafeinasi. Metode yang umum digunakan untuk menurunkan kadar kafein (dekafeinasi) ini adalah melaui proses pengolahan secara basah (fermentasi). Penelitian berkaitan dengan dekafeinasi biji kopi sudah banyak dilakukan diantaranya dengan kolom tetap menggunakan pelarut air (Mulanto et al., 2001), menggunakan alat dekafeinasi biji kopi (Rejo et al., 2011), dan dengan sistem pengukusan (steamer) (Suharman dan A gafar, 2017). Namun mengingat penggunanya adalah Industri Rumah Tangga, maka tentu pengolahan seperti ini sangat membutuhkan biaya yang mahal. Oleh karena itu diperlukan suatu alternatif lain dengan biaya yang relatif murah yakni dengan perendaman dalam larutan alkali .

Larutan alkali yang biasa ditambahkan pada saat proses fermentasi ini diantaranya adalah $\mathrm{K}_{2} \mathrm{CO}_{3}, \mathrm{Na}_{2} \mathrm{CO}_{3}$ dan $\mathrm{NaOH}$. Semakin basa alkali yang digunakan pada fermentasi kopi robusta maka penurunan terhadap kadar kafein semakin tinggi (Primadia Almada, 2009) . Pemberian perlakuan 
alkali pada kopi yang tidak difermentasi dapat memperbaiki mutu biji kakao yang dihasilkan ditandai dengan terjadinya penurunan kadar air (Sudarmadji et al., 1996). Namun belum ada penelitian yang menyatakan berapa konsentrasi optimum dari alkali ini tanpa menurunkan mutu dari kopi bubuk yang dihasilkan. Maka dari itu pada penelitian ini dilakukan untuk mencari kadar optimum dari larutan alkali yang digunakan, dengan harapan diperoleh kadar kafein yang rendah, tanpa mengenyampingkan mutu kopi bubuk yang dihasilkan.

Tujuan penelitian ini adalah (a) Mengetahui pengaruh konsentrasi alkali terhadap kadar kafein, dan mutu kopi bubuk yang dihasilkan, dan (b) Menentukan konsentrasi alkali yang paling tepat digunakan agar diperoleh kadar kafein dan mutu kopi bubuk yang sesuai dengan SNI.

\section{METODOLOGI PENELITIAN}

\section{A. Waktu dan Tempat}

Penelitian dilakukan di Laboratorium Analisis dan Hasil Pertanian Prodi Teknologi Industri Pertanian Unidha, Teknologi Hasil Pertanian Fateta Unand dan Laboratorium Analisis dan Bahan Alam Fakultas Farmasi Unand. Penelitian ini dilakukan pada Bulan April - Agustus 2019 mulai dari persiapan penelitian hingga selesai.

\section{B. Bahan dan Alat}

Bahan yang digunakan dalam penelitian ini adalah kopi robusta yang diperoleh dari petani yang ada di Alahan Panjang Kabupaten Solok. Bahan baku percobaan yang digunakan buah kopi utuh dengan kematangan cukup ditandai dengan warna merah pada buah atau umur 300-350 hari setelah Anthesis. Sedangkan bahan kimia yang digunakan yakni $\mathrm{NaOH}$ dan $\mathrm{Na}_{2} \mathrm{CO}_{3}$. Alat yang digunakan adalah HPLC dengan spesifikasi aglent technologies I 120 Compact LC, timbangan analitik, pengaduk, corong kertas saring whatman no.1, penangas air, membrane filter, alat-alat gelas, oven, dan desikator.

\section{Rancangan Penelitian}

Rancangan penelitian yang digunakan adalah Rancangan Acak Lengkap (RAL) dengan 10 Perlakuan dan 3 ulangan. Setelah data diperoleh kemudian data diolah dengan uji statistik ANOVA. Jika berbeda nyata dilanjutkan dengan Uji DMRT pada taraf 5\%

\section{Pelaksanaan Penelitian}

Buah kopi yang diperoleh dari petani disortasi. Sortasi bertujuan untuk memisahkan buah kopi yang busuk dan buah kopi yang masih berwarna hijau maupun hijau kekuningan. Buah kopi yang dijadikan sebagai sampel penelitian adalah buah kopi yang berwarna merah atau umur 300-350 hari setelah Anthesis. Buah kopi segar yang sudah disortasi ditimbang masing-masing dengan berat $1 \mathrm{~kg}$, kemudian direndam dalam konsentrasi Alkali $\mathrm{NaOH} 3 \%$ (perlakuan A1), 3.5\% (perlakuan A2), $4 \%$ (perlakuan A3), $4.5 \%$ (perlakuan A4), dan 5\% (perlakuan A5) serta konsentrasi alkali $\mathrm{Na}_{2} \mathrm{CO}_{3} 6 \%$ (perlakuan B1), 6.5\% (perlakuan B2), 7\% (perlakuan B3), 7.5\% (perlakuan B4) dan 8\% (perlakuan B5) selama 24 jam.

Setelah dilakukan perendaman, buah kopi dikeringkan dengan penjemuran dibawah sinar matahari. Buah kopi yang sudah kering kemudian dilakukan pemisahan biji kopi dengan lapisan kulit luarnya menggunakan huller. Proses selanjutnya biji kopi di sangrai pada suhu $190{ }^{\circ} \mathrm{C}$ selama 10 menit (Edvan. B and Edison.R, 2016) dan dilakukan pengicilan ukuran dengan proses penggilingan.

Bubuk kopi yang dihasilkan kemudian dilakukan pengujian yakni (1) kadar air, metode AOAC (Official Method of Analysis) 2005, (2) kadar abu, metode AOAC (Official Method of Analysis) 2005 dan (3) kadar kafein dengan metode HPLC. Diagram alir penelitan disajikan pada Gambar 1. 


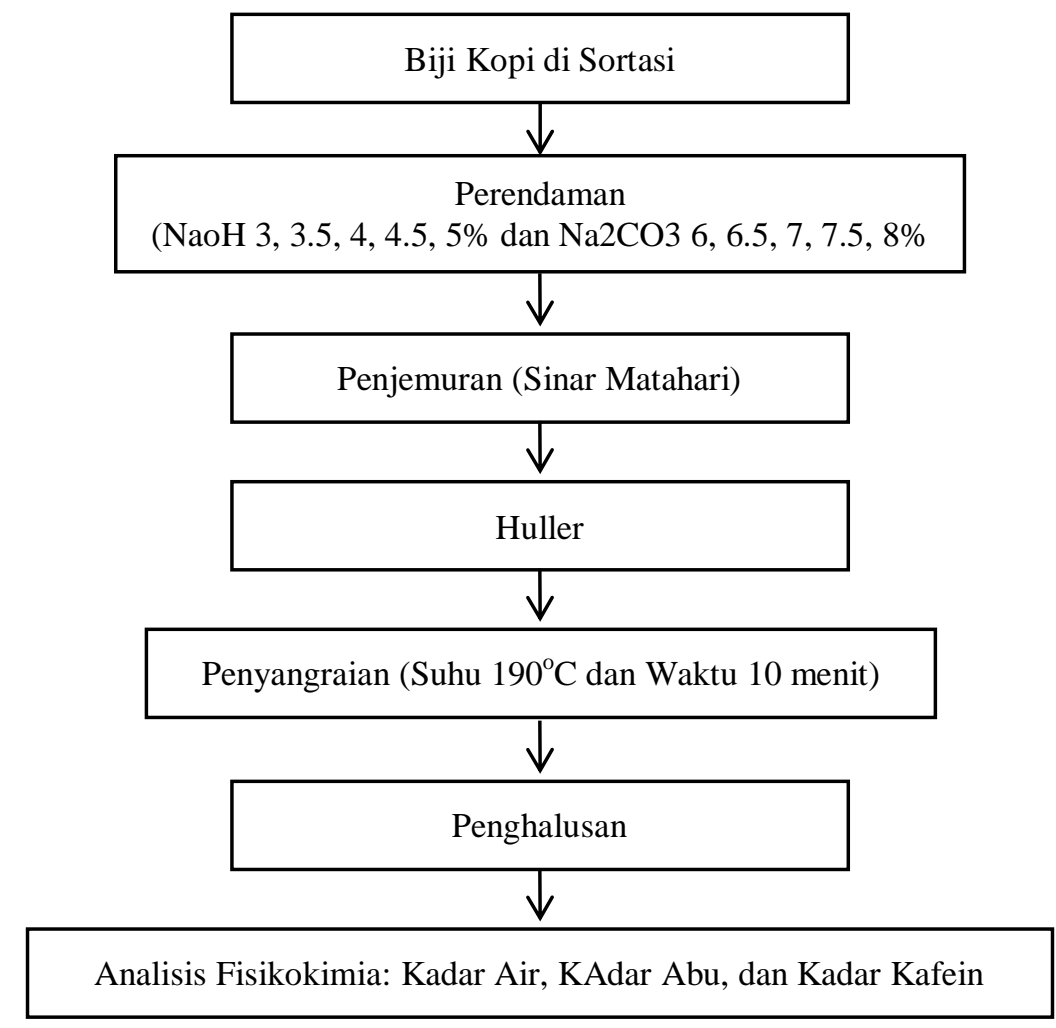

Gambar 1. Diagram Alir Penelitian

\section{HASIL DAN PEMBAHASAN}

\section{A. Kadar Air}

Tabel 1 menunjukkan kadar air kopi bubuk yang diperoleh setelah perendaman dalam larutan alkali berkisar antara 1,3682\% - 1,7072\%. Kadar air terendah dihasilkan pada perlakuan B5 (perendaman dengan perlakuan penambahan larutan alkali Alkali $\mathrm{Na}_{2} \mathrm{CO}_{3} 8 \%$ yaitu sebesar 1,3682\%, sedangkan kadar air tertinggi dihasilkan pada perlakuan B1 (perendaman dengan perlakuan penambahan larutan alkali $\mathrm{Na}_{2} \mathrm{CO}_{3} 6 \%$ ) sebesar $1,7072 \%$.

Tabel 1. Pengaruh Perlakuan terhadap Kadar Air Kopi bubuk Dekafeinasi

\begin{tabular}{ccl}
\hline Perlakuan & Kadar Air $(\%)$ \\
\hline A1 & 1,5655 & cd \\
A2 & 1,4778 & b \\
A3 & 1,4997 & bc \\
A4 & 1,6606 & f \\
A5 & 1,5509 & cd \\
B1 & 1,7072 & g \\
B2 & 1,6524 & ef \\
B3 & 1,5756 & de \\
B4 & 1,6137 & def \\
B5 & 1,3682 & a \\
\hline
\end{tabular}

Hasil analisis ragam menunjukan bahwa perlakuan penambahan larutan alkali berpengaruh nyata terhadap kadar air kopi bubuk setelah proses dekefeinasi. Perbedaan kadar air pada kopi bubuk dapat diakibatkan oleh perbedaan ukuran biji yang digunakan. Mulato (2001) menyatakan bahwa perbedaan ukuran biji kopi dapat mempengaruhi kadar air yang terdapat dalam biji kopi. Selain itu jumlah sel-sel penyusun yang ada di dalam biji kopi juga sangat mempengaruhi (Primadia Almada, 2009). Kadar air merupakan persentase kandungan air bahan yang biasanya dinyatakan secara berat 
basah (wet basis) atau berdasarkan berat kering (dry basis). Kadar air pada kopi sangat berpengaruh pada pertumbuhan mikroorganisme, khususnya jamur, tetapi kadar air hasil penelitian ini masih jauh lebih kecil dari kondisi optimum untuk pertumbuhan jamur okratoksin (Gafar, 2018).

Secara keseluruhan karakteristik kopi bubuk telah memenuhi Standar Nasional Indonesia (SNI 01-3542-2004) tentang kopi bubuk. Menurut SNI 01-3542-2004 kadar air maksimum kopi bubuk adalah 7\%. Hal ini menunjukkan bahwa kopi bubuk yang dihasilkan pada penelitian ini telah memenuhi syarat untuk dipasarkan sebagai kopi bubuk dekafeinasi.

\section{B. Kadar Abu}

Kadar abu penting untuk mengetahui besarnya kandungan mineral yang terdapat dalam sampel bahan. Semakin tinggi kadar abu yang terkandung didalam bahan maka semakin semakin buruk kualitas dari bahan pangan tersebut (Sudarmadji et al., 1996). Tabel 2 menunjukkan bahwa nilai kadar abu kopi bubuk yang diperoleh setelah perendaman dalam larutan alkali berflutuaktif berkisar antara 4, $5217-5,9694 \%$. Kadar abu terendah terdapat pada perlakuan B1 (larutan alkali $\mathrm{Na}_{2} \mathrm{CO}_{3}$ $6 \%$ ) sebesar 4,5217\%, sedangkan yang tertinggi terdapat pada perlakuan A5 (larutan alkali $\mathrm{NaOH}$ $5 \%$ ) yaitu 5,9694\%. Semakin tinggi konsentrasi alkali yang ditambahkan pada saat perendaman, maka semakin tinggi pula kadar abu yang terdeteksi pada kopi bubuk dekafeinasi. Yuhandini et al., (2008) mutu kopi tidak akan baik jika kandungan mineral terlalu tinggi, produk tidak bersih yang akan berakibat pada semakin meningkatnya kadar abu yang dihasilkan. Selain itu berdasarkan penelitian oleh Putri et al., (2017) proses pencucian setelah perendaman mengakibatkan kadar abu pada biji kopi menurun, air pencucian akan membilas sisa-sisa mineral yang larut dan dibawa oleh air pencuci sehingga komponen mineral yang tertinggal menjadi lebih sedikit.

Tabel 2. Pengaruh Perlakuan terhadap Kadar Abu Kopi Bubuk Dekafeinasi

\begin{tabular}{ccc}
\hline Perlakuan & Kadar Abu $(\%)$ \\
\hline A1 & 5,4238 & $\mathrm{~cd}$ \\
A2 & 4,8631 & $\mathrm{~b}$ \\
A3 & 5,6348 & $\mathrm{~d}$ \\
A4 & 5,4993 & $\mathrm{~d}$ \\
A5 & 5,9694 & $\mathrm{e}$ \\
B1 & 4,5217 & $\mathrm{a}$ \\
B2 & 4,6153 & $\mathrm{a}$ \\
B3 & 4,7155 & $\mathrm{ab}$ \\
B4 & 4,6573 & $\mathrm{c}$ \\
B5 & 5,2674 & $\mathrm{ab}$ \\
\hline
\end{tabular}

Namun dari hasil analisis sidig ragam menunjukkan bahwa perlakuan penambahan larutan Alkali pada beberapa konsentrasi berpengaruh nyata terhadap kadar abu yang dihasilkan. Jika dilihat dari karakteristik mutu kopi bubuk berdasarkan Standar Nasional Indonesia (SNI 01-3542-2004) tentang kopi bubuk. Kadar abu maksimum kopi bubuk adalah 5\%. Hal ini menunjukkan bahwa kopi bubuk dengan perlakuan A (konsentrasi Alkali NaOH 3, 3.5, 4, 4.5 dan 5\%) dan perlakuan B5 (konsentrasi alkali $\mathrm{Na}_{2} \mathrm{CO}_{3} 8 \%$ ) yang dihasilkan pada penelitian ini tidak memenuhi syarat untuk dipasarkan sebagai kopi bubuk dekafeinasi.

\section{Kadar Kafein}

Tabel 3 menunjukkan bahwa nilai kadar kafein kopi bubuk dekafeinasi berkisar antara 1,0490,954\%. Kadar kafein terendah terdapat pada perlakuan A5 (konsentrasi larutan alkali $\mathrm{NaOH} 5 \%$ ) sebesar $0,954 \%$, sedangkan yang tertinggi terdapat pada perlakuan $\mathrm{B} 1\left(\mathrm{Na}_{2} \mathrm{CO}_{3} 6 \%\right)$ yaitu $1,049 \%$. Pada penelitian ini penurunan kadar kafein hanya berkisar $67 \%$.

Hasil analisis ragam menunjukkan bahwa penambahan larutan alkali berpengaruh nyata terhadap kadar kafein kopi bubuk yang dihasilkan. Namun pemberian larutan alkali pada perlakuan A5, memberikan hasil terbaik dengan diperolehnya kadar kafein terendah, namun tidak berbeda dengan perlakuan A5, B3, B4 dan B5. 


\begin{tabular}{|c|c|c|}
\hline \multicolumn{3}{|c|}{ Tabel 3. Pengaruh Perlakuan terhadap Kadar Kafein Kopi bubuk Dekafeinas } \\
\hline Perlakuan & Kadar $\mathrm{K}$ & \\
\hline A1 & 1,032 & $\mathrm{~b}$ \\
\hline A2 & 1,008 & b \\
\hline A3 & 1,027 & b \\
\hline A4 & 0,984 & $a b$ \\
\hline A5 & 0,954 & $\mathrm{a}$ \\
\hline B1 & 1,049 & b \\
\hline B2 & 1,036 & b \\
\hline B3 & 0,978 & $a b$ \\
\hline B4 & 0,979 & $a b$ \\
\hline B5 & 0,979 & $a b$ \\
\hline
\end{tabular}

Penurunan kadar kafein dapat diakibatkan oleh beberapa faktor, diantaranya penambahan larutan alkali, lama waktu perendaman, dan ukuran biji. Mulanto et al. (2001) menyatakan bahwa penurunan kadar kafein pada proses dekafeinasi dapat diakibatkan oleh waktu pelarutan dan ukuran biji kopi. Semakin lama perendaman, semakin kecil ukuran biji maka jumlah kafein yang terekstrak juga akan semakin meningkat. Hanifah dan Kurniawati (2013) menyatakan bahwa NaOH merupakan basa kuat yang dapat mereduksi kafein terlebih dahulu kemudian dilanjutkan dengan larutan alkali $\mathrm{Na}_{2} \mathrm{CO}_{3}$. Berdasarkan hasil penelitian Zarwinda dan Sartika (2019), proses kelarutan kafein diawali oleh pemecahan senyawa ikatan kompleks kafein akibat pelakuan panas, dengan semakin tinggi suhu pelarut maka proses pemecahan akan berlangsung lebih cepat.

\section{KESIMPULAN}

1. Penambaan larutan Alkali berpengaruh nyata terhadap kadar air, kadar abu dan penurunan kadar kafein kopi bubuk.

2. Kopi bubuk dekafeinsasi yang dihasilkan memiliki kadar air berkisar 1,3682\% - 1,7072\%, kadar abu 4, $5217-5,9694 \%$, dan kadar kafein berkisar antara 1,049- 0,954\%.

3. Perlakuan terbaik terdapat pada perlakuan penambahan larutan alkali $\mathrm{Na}_{2} \mathrm{CO}_{3} 7 \%$ dengan kadar air $1,5756 \%$, kadar abu $4,7155 \%$ dan kadar kafein $0,978 \%$.

\section{DAFTAR PUSTAKA}

Badan Pusat Statistik, 2016. Statistik Perkebunan Indonesia 2015-2017. Badan Pusat Statistik, Jakarta. Edvan, B.T., Edison, R., 2016. Pengaruh Jenis dan Lama Penyangraian pada Mutu Kopi Robusta (Coffea robusta). Jurnal Agro Industri Perkebunan . Vol. 4 No. 1. doi: 10.25181/aip.v4i1.34

Gafar, P.A., 2018. Proses Penginstanan Aglomerasi Kering dan Pengaruhnya terhadap Sifat Fisiko Kimia Kopi Bubuk Robusta (Coffea robusta Lindl. Ex De Will). Jurnal Dinamika Penelitian Industri Vol. 29 No 2. doi: -

Hanifah, N., Kurniawati, D., 2013. Pengaruh Larutan Alkali dan Yeast terhadap Kadar Asam, Kafein, dan Lemak pada Proses Pembuatan Kopi Fermentasi. Jurnal Teknologi Kimia dan Industri 2, $162-168$.

Mulanto, S., Widyatomo, S., Lestari, H., 2001. Pelarutan Kafein Biji Kopi Robusta dengan kolom Tetap Menggunakan Pelarut Air. Jurnal Pelita Perkebunan 17, 97-109.

Primadia Almada, D., 2009. Pengaruh Peubah Proses Dekafeinasi Kopi dalam Reaktor Kolom Tunggal terhadap Mutu Kopi. Thesis.

Putri, J.M.A., Nocianitri, K.A., Putra, N.K., 2017. Pengaruh Penggunaan Getah Pepaya (Carica papaya L.) pada Proses Dekafeinasi terhadap Penurunan Kadar Kafein Kopi Robusta. Media Ilmiah Teknologi Pangan Vol. 4, No.2, 138 - 147. doi: - 
Rejo, A., Rahayu, S., Panggabean, T., 2011. Karakteristik Mutu Biji Kopi pada Proses Dekafeinasi. Jurusan Teknologi Pertanian Faperta Unsri. http://eprints.unsri.ac.id/22, diakses 2 februari 2020.

Sudarmadji, S., Haryono, B., Suhardi, 1996. Analisis Bahan Makanan dan Pertanian. Liberty, Yogyakarta.

Suharman, A gafar, P., 2017. Teknologi Dekafeinasi Kopi Robusta untuk Industri Kecil dan Menengah (IKM). Jurnal Dinamika Penelitian Industri 28. doi: 10.28959/jdpi.v28i2.

Yuhandini, I., Rejo, A., Hasbi, 2008. Analisis Mutu Kopi Sangrai berdasarkan Tingkat Mutu Biji Kopi Beras. Program Studi Teknik Pertanian UNSRI Indralaya.

Zarwinda, I., Sartika, D., 2019. Pengaruh Suhu dan Waktu Ekstraksi terhadap Kafein dalam Kopi. LJ 6, 180. doi: $10.22373 /$ lj.v6i2.3811 